\title{
Legal Effect of the Informed Consent of the Patients
}

\author{
Jinguo Wang \\ Department of Urology \\ The First Hospital of Jilin University \\ Changchun, China \\ wangjinguolily@163.com
}

\author{
Na Wang* (corresponding author) \\ Department of Anesthesiology \\ The First Hospital of Jilin University \\ Changchun, China \\ wangna080613@163.com
}

\begin{abstract}
To identify the situations requiring information of patients and how the doctors inform and determine the exemption of the doctors by interpreting Tort Liability Law which provides this principle in the basic aspect of civil law for the first time. The informed consent principle of patients is the one of the fundamental principles of modem medical 1aw. But in its actual operation, there are some problems. The informed consent principle of patients should include the doctors' obligation to inform and the patients.
\end{abstract}

\section{Keywords_-Informed consent; law; patient}

\section{INTRODUCTION}

In order to ease the doctor-patient relationship in an increasingly tense, build a harmonious medical mechanism, strengthen the protection of patients' right of informed consent is particularly important. Informed consent right is the most important manifestation of patients with medical decisions, it requires that the prescriptions before the implementation of the medical behavior, must be the related medical information to patients, and obtain the consent of the patient, or it is to form the violation of patients' body and health, need to assume legal responsibility.

\section{LEGAL EFFECT OF THE INFORMED CONSENT}

Western developed countries have established a relatively perfect system of right of informed consent, emphasis on respect for patients' right of informed consent is conducive to building a harmonious doctor-patient relationship. The country's relevant law whiles the informed consent, but there are still some shortcomings. Informed consent, it is to point to patients in health providers to provide sufficient information necessary to their medical decisions made on the basis of the rights of medical consent.

A. Informed consent right is one of the basic rights of patients and the embodiment of the patients' self-determination in the medical field.

Informed consent right is in the change of the doctorpatient relationship and produce under the background of the influence of the human rights campaign; in Anglo-American law system and continental law system have been developing in the country's laws. Law of our country although also explicitly admitted patients right of informed consent, but there are still too principle and general, imperfect remedy deficiency due to prescriptions inform obligation is the important basis of constructing the informed consent system, therefore, in this part separately introduced the prescriptions of the inform obligation. Required to inform obligation has advised referral told, for the consent of the patients with effective informed, rehabilitation guidance told three types. The author thinks that, to the consent of the patients with effective inform obligation is the research object of this article. This paper discusses the prescriptions of the inform obligation legal nature. The prescriptions of the inform obligation standard, and points out that our country should adopt double standards. After introduced the general told the content, the author also at surgery, anesthesia, blood transfusions, injections, medication, and clinical experimental medical specific medical behavior told content is introduced in detail. The fifth section is required to inform obligation. In order to make patients really understand informed content, an effective, with the approval of the prescriptions should take appropriate informed way and pay attention to inform the language and skills.

When patients have agreed to ability, the right of informed consent by patients themselves has agreed to ability, by others to exercise the right of informed consent. The second section is agreed. Agree to accept patients with medical behavior intention is true, will directly affect the patients agree to effect. The third section is agreed. Agree that the content is whether patients accept the scope of medical behavior and accept how much. The author believes that the prescriptions must be carried out in patients agreed to under the scope of medical practice, unless there is an emergency can expand the scope of agreed. The fourth section is the right of informed consent form. There are mainly express (written and oral) and implied in two ways. In addition to law stipulates clearly informed consent form, should be taken to adopt other ways generally have the same legal effect.

Prescriptions patients informed consent right infringement damage to patients, the breach of contract and tort will happen. As for patients should be in what cause by the lawsuit, the author thinks that, liability for breach of contract and tort liability has its characteristic each, should add option to patients. Finally, the article respectively from the Angle of the liability for breach of contract and tort liability, analysis between patients informed consent right infringement responsibility. 
Informed Consent rights (The Right of Informed Consent) refers to the patients in health providers to provide sufficient information necessary to their medical decisions made on the basis of the rights of medical Consent [1]. Before understanding the definition, must first clear right subject party, compulsory subject, the meaning of the prescriptions party including patients and their close relatives.

Patients often also referred to as a patient, namely, the human body physiology, mental state, social adaptation state is abnormal people [2]. Therefore, patients should be understood as those who have lost their health status. Therefore, life is healthy but accept medical services, such as the need to pursue beauty, accept medical beauty services will not be discussed in this paper. The patient's close relatives, generally refers to the patient's spouse, parents, children, brothers and sisters, paternal grandparents, father, parents, grandchildren or maternal grandchildren.

\section{B. The prescriptions, medical institutions and medical personnel.}

Medical institutions, is in our country, in accordance with the law by the registration and obtain the "practice license of medical institution", two categories, including hospitals and individual clinics. Medical personnel, is refers to the administrative department of public health, through examination and approval or admit, obtain the corresponding qualification and practice certificate at all levels.

All kinds of health technical personnel include epidemic prevention staff, staff, nurses and other technical personnel. Provide medical information can only be the people in the medical institutions, medical staff. But based on the duty behavior, the body of the violation of patients' informed consent, the responsibility should be medical institutions.

In our country, the hospital medical institutions is the main part of a normal hospital according to the patient's medical treatment processes, often set consulting service desk, registered room, waiting area, inspection area, pharmacies, injection area, operating room, such as the inpatient and cashier's department. In the whole process of patients hospitalized, will come into contact with different in different stages of medical staff, need access to medical information is also different. Patient has the right to know in the process of the treatment of medical information is quite widespread; it actually is respect for the patients' right to know. Patients' right to know, that is, patients in the process of diagnosis and treatment of medical institutions can be the right to demand to know all the necessary information [3].

Patients' informed consent right of medical behavior is "informed consent" problem. Informed consent right of patients with including "informed" and "agree" two parts. "Informed", refers to the patient has the right to the information necessary to make medical decisions known. Therefore, "knowledge" in the right of informed consent and patients' right to know there is a difference between. The former knowledge scope is limited to patients with medical information needed for the agreed to decision making, such as prescriptions and want treatment, the name of the concrete implementation steps and information such as risk treatment. The scope of the latter is more extensive, as long as it is related to the patients received medical care information; patients have the right to knowledge. As a result, patients informed consent right of the "informed" clearly less than the patients' right to know in the range, only involves the medical information related to "agree". The so-called "agree", refers to the fully informed, on the basis of the prescriptions recommend patients to accept or reject the medical behavior. Any the implementation of the medical behavior must be on the premise, the consent of the patient or infringement. Therefore, patients are illegal deterrent for medical behavior [4].

Patients' right of informed consent "informed" and "agree" are inseparable in the unity of the whole. On the one hand, people agree with the premise and foundation. Because of medical is a professional high science, patients because do not have medical professional knowledge; it is difficult to understand the related medical information. This requires that the prescriptions in patients can understand language and manner, informed patient medical information needed for the agreed decision. Only on the basis of knowledge of agree is effective, is the premise of legalization of medical practice. Agreed, on the other hand, is close to the purpose and value. Patients after obtain the necessary and sufficient information, to these information analysis, weigh the pros and cons, in the end the most beneficial to their health medical decision agreed to or refuse to medical practice. So, "informed" and "agree" the right to informed consent is patients indispensable two aspects. But at the same time should also note that in the patients informed consent right of this phrase, the legal status of the two is not completely the same, because the main body of the phrase is patients, emphasizes the respect for the patients' medical self-determination, therefore, agree is the core and key. Knowledge exists in order to assist the patient to make medical decisions, is to agree with the service, around agreed.

In the doctor-patient relationship, although patients with prescriptions have equal status, but because of the complexity of the medical profession, make as ordinary people difficult to understand related medical information of patients. Information unequal sex caused patients and health providers substantial inequality exists in the position, this also caused the patients' mistrust of the prescriptions, once appear, medical disputes and patients tend to the occurrence of medical damage boils down to is the responsibility of the prescriptions, cause the doctorpatient contradiction intensified on both sides, not conducive to the establishment of a harmonious relationship between medical. The right of informed consent emphasizes respect for patients' medical self-determination, requirements prescriptions shall provide relevant information in the form of patients would be able to understand, it's made up for the inadequacy of the patient's medical knowledge, improving both doctors information is wrong, and so on. This aspect is helpful to strengthen the trust relationship between doctor and patient, make patient autonomy to make medical decisions, and actively cooperate with the prescriptions of treatment; , on the other hand, when the medical disputes, informed consent has been clear about the patient rights and obligations of both parties, this for the convenience of litigation proof, eventually establish a positive role in promoting the harmonious doctorpatient relationship [5]. 
The legal nature of patients' right of informed consent should be formed. Right of formation, refers to the right holder according to the legal nature of their patients informed consent right should be formed. Right of formation, refers to the right holder in accordance with their own behavior, make oneself or common law relationship with others the right to change [5]. Prescriptions for patients of medical behavior are legal depend on whether patients on the basis of knowledge to make effective agreed. If required under the condition of the ground without relief, without the consent of the patients with the implementation of the medical behavior, even if the prescriptions is for the purpose of treatment, also due to the violation of patients' body integrity established tort. Prescriptions in the implementation of the medical behavior, on the contrary, fully fulfilled inform obligation to patients and get approval, medical behavior is due to the consent of the patients had the legitimacy. Thus establish the patient with medical behavior as the main object of legal relation, the legal relationship, is based on patients with unilateral assent to medical practice, full compliance with the right of formation characteristics. As a result, patients' informed consent right belongs to the legal nature of right of formation [6].

The exercise of rights needs to use a certain behavior. Right to exercise their rights refers to the human to realize the significance of rights in accordance with the rights and power and activities. Patients' informed consent right is mainly done by "informed consent".

\section{The legal issues involved in patients' right of informed consent}

The understanding of informed consent can from the following two aspects to study. First of all, "behavior" informed consent is the legal behavior or quasi juristic act? Socalled legal act, is a kind of legal facts, refers to the civil main body to set up, change or terminate civil rights and obligations for the purpose, expressed as a means for elements, to civil legal effect. Similar legal act, contain the intention or some specific contents of the mental representation, but the meaning or not directly pursue spirit said to have no direct implementation of the legal effect, the legal effect, is determined according to the law. Must have legal act can be divided into meaning again notice, ideas, feelings notice three types. 6 legal behavior and an obvious difference between the prospective legal act is: the former is based on the legal effect of the actor's meaning, while the latter depends entirely on the rule of law." Agreed to act so, in the judgment" is a legal act or quasi legal behavior, we can as a breakthrough. As is known to all, the object of medical practice is the patient's body, to cure diseases, health providers must to contact with the patient's body or intrusion. Tong said that, for the purpose of medical integrity violation to the body, also the objective requirement of injuries. All landowners as patients, it is the decision to agree to treat, is necessary to restore their health to get himself into a dangerous situation. It can be said that any patient behavior is a safe and successful treatment of hope, are not willing to undertake any medical risks. As a doctor, because of the complexity of the medical science and the individual difference of patients makes the medical behavior will be a certain risk, if the entire risk is to the requirements in the prescriptions of medical behavior of all responsibility, so doctors believe that no one is willing to engage in the profession. Patients in order to balance the contradictory relations, law agrees are against the law to stop for medical behavior in patients with effective agrees to exempt from prescriptions in fulfill the reasonable duty of care under the implementation of the responsibility of the medical behavior of reasonable risk." Accordingly," informed consent "legal effect is not the result of restore autonomy, but from the rule of law, so it is legal act.

Second, "informed consent" is related with the medical contract behavior. Patients to medical institutions for medical treatment, prescriptions for patients heal, is a kind of medical contract relationship between the two. Based on the theory of contract law, the establishment of the contract shall have two stages of offer and acceptance. Tong said that patients request registration behavior for an offer, required to pay the behavior of the booking form is a promise. However, to conclude the proposed medical contract offer compared with the general civil contract offer has its particularity. For general civil contract, the content of the offer must be specific. And patients go to a hospital seeing a doctor is to find out the cause, treatment of disease. Therefore, before the doctor for the diagnosis, most patients do not know their own cause and disease. Go to the hospital to register, but patients should be roughly know the disease which section, if I do not know, will be their main disease told registered personnel, registered staff would be told that they should be to see which section. Conclusion of the medical contract, therefore, the proposed offer content is to inform the prescriptions about the disease and general hope treated prescriptions for the disease. The prescriptions to register patient behavior is promised, medical contract is reached.

Medical contract behavior, therefore, is don't need any other legal ACTS can exist independently belong to the Lord Legal act. Prescriptions according to patients' disease next, take the specific diagnosis and treatment behavior, is in the medical contract. Under the premise of, on the status of attached to the medical contract, therefore belongs to from a legal act. The main legal behavior does not set up, invalid, or destroy, from the legal act also does not set up, invalid, or destroyed. The prescriptions are the implementation of specific diagnosis and treatment. Behavior before, must fully fulfill their obligation to inform and obtain patients agree. So, patients informed consent behavior is attached. And on the specific diagnosis and treatment behavior of legal act, should also be on the premise of the establishment of the medical contract. From that point of view, the relationship between the behavior of informed consent and medical contract behavior is similar to the legal behavior and the main legal behavior. But again there is particularity, which is mainly manifested in informed consent behavior on effectiveness are not fully attached to the medical contract. Adult patients, for example, a sound mind in a do not have personal clinic practice qualification, in fact. Specific behavior before treatment, the doctor to the patient to perform adequately inform obligation and has obtained the consent of the patients in between the main body of discomfort, between the medical contract should be invalid, so patients informed consent behavior should also be invalid then? The author 
thinks that, as long as the physician comprehensive information required to properly informed patient to make medical decisions, and there is no fraud and compulsive behavior, it shall be deemed as the consent of the patients is effective. In the event of medical injury, patients may demand the prescriptions on the grounds that the medical contract is invalid to assume corresponding responsibility.

Illegal behavior is one of the tort liability of elements, but sometimes for some reason, can generate resistance is in violation of the legal effect of the existence of the infringement behavior person could reason from bear legal responsibility. The victim consent is a tortfeasor exemption for tort is because of the existence of the reason no longer has the illegality. The victim consent, it is to point to the victim is the occurrence of specific behavior or other people about their rights and interests of specific damage consequences shall be agreed and in the will of the external performance. In ancient Rome had "behavior is not agreed as illegal" method of proverbs, the victim consent can exempt from tort liability law effect has become the most common rules of the country. Patients with the consent of the patient is allowed to prescriptions to invasive medical practice on its body, the patient's reasonable effective agreed to exempt from prescriptions in doing their duty of care under the implementation of medical behavior of reasonable risk responsibility, is illegal deterrent for medical behavior. Patients, therefore, agree with the victim is the same in essence, belongs to the one with the consent of the victim. But patients agreed to have its particularity, that is, the consent of the patients is effective, depending on the prescriptions of told an obligation. Before the implementation of the medical behavior, cure illness, treatment, treatment must be risk to the patient information such as specification, let people understand the information necessary to agree with decision making, based on this to agree is effective, to develop resistance but illegal medical behavior legal effect.

\section{CONCLUSION}

Patients' right of informed consent on the legal nature belongs to the right of formation, in the whole medical contract is attached on the specific diagnosis and treatment behavior. The patients informed consent right is the legalization of medical practice without the consent of the patients on the implementation of the premise, medical behavior is illegal behavior, need to assume legal responsibility.

\section{REFERENCES}

[1] Yajun Liu, Xinxi Xu, Fu Niu, Shulin Tan. Study on Overpressure Protection System of Air Contaminations for Mobile Medical Shelters [A]. Proceedings of 2014 2nd International Conference on Applied Mechanics, Materials and Manufacturing (AMMM 2014) [C]. 2014

[2] Hongli Zhai, Yujia Zhang. On the Obligation to Supply Medical Documents in Medical Malpractice Litigations [A]. Proceedings of 2014 4th International Conference on Applied Social Science (ICASS 2014 V52)[C]. 2014

[3] Kadi Lubi, Triin Vihalemm, Pille Taba. Illness-related Information Seeking: The Case of Parkinson's Disease Patients [A]. Proceedings of 2014 2nd International Conference on Social Science and Health(ICSSH 2014 V59)[C]. 2014

[4] Ronald P. Strauss, Sohini Sengupta, Sandra Crouse Quinn, Jean Goeppinger, Cora Spaulding, Susan M. Kegeles, Greg Millett.

[5] National Bioethics Advisory Commission.

[6] Aaron Ciechanover. The Personalized Medicine Revolution:Are We Going to Cure All Diseases and at What Price? 